Textures and Microstructures, 1988, Vols. 8 \& 9, pp. 579-598

Reprints available directly from the publisher

Photocopying permitted by license only

C 1988 Gordon and Breach Science Publishers Inc.

Printed in the United Kingdom

\title{
SAECP Combined with Quantitative Image Analysis -an Improved Tool for Texture Analysis
}

\author{
W. LORENZ and H. HOUGARDY \\ Max-Planck-Institut für Eisenforschung GmbH, Düsseldorf, FGR
}

(Received September 24, 1987; in final form January 5, 1988)

\section{Dedicated to the memory of Professor Günter Wassermann}

\begin{abstract}
A selected area electron channelling pattern (SAECP), which allows the determination of the orientation of individual grains in polished steel specimens, can be obtained with a scanning electron microscope. The different methods to determine the orientation of the grains from the measured pattern are summarized. A minimum grain diameter of about $7 \mu \mathrm{m}$ is required for orientation determination and the maximum error for the determination of $(h k l)$ is about $2^{\circ}$, and about $4^{\circ}$ for [uvw]. The total time needed for the determination of the orientation of 400 grains is in the range of 60 hours. Different representations of results are discussed. An example shows that the measurement of single orientations can give more information on the mechanisms of recrystallization than an investigation by $\mathrm{x}$-rays only.
\end{abstract}

KEY WORDS: Scanning electron microscopy, channelling patterns, image analysis, ODF analysis, orientation correlation, low carbon steel, recrystallization texture.

\section{INTRODUCTION}

For the description of textures in materials, the orientation distribution function (ODF) is generally used (Bunge 1982, Hansen et al., 1978). The ODF is generally determined by $x$-ray or neutron 
diffraction (Bunge 1986, Welch 1986) with automated measuring techniques (Klein, Bunge, 1986, Hirsch et al., 1986). The result is an ODF representing a statistical orientation distribution of the volume from which the $\mathrm{x}$-ray or neutron diffraction originates. There is no information on the orientation of individual crystals and their relative positions within the microstructure. This information however, is necessary to understand the mechanisms of texturedevelopment. The orientations of individual crystals can be obtained by transmission electron microscopy (TEM) or scanning electron microscopy (SEM). In TEM the orientation of each crystal can be determined by means of Kikuchi patterns (Heimendahl, 1970, Weiland, Schwarzer, 1986). But, to do that it is necessary to prepare thin foils which represent only a small area of the specimen. A large area can be investigated by selected area electron channelling patterns (SAECP) produced by SEM but there are other limitations: the minimum size of a crystal to be measured must be in the range of $7 \mu \mathrm{m}$ in diameter, and the dislocation density must be less than approximately $10^{10} / \mathrm{cm}^{2}$ (Weiss et al., 1971, Klaffke, 1978). Nevertheless, the measurement of the orientations of many grains on a large area by SEM opens a wide field of applications in texture analysis (Watanabe 1984, Lorentz, in preparation). In the following paragraphs an improved technique for the determination of the orientation of individual grains in deep drawing steels by SEM is described. Additionally an example of a practical application is given.

\section{PRINCIPLES OF THE TECHNIQUE}

The physical background of the method is described elsewhere in detail (Kubalek, 1973, Reimer, Pfefferkorn, 1977). In the following the principles are only briefly summarized as far as is necessary to understand the determination of the orientation.

To get selected area electron channelling patterns the electron beam of the SEM has to be focussed in a fixed position on the surface of the specimen. At this position the incident angle of the electron beam is changed in two vertical directions (Lane et al.) or on concentric cones (Essen et al., 1971, Thönnessen, 1987) with angles $0<\alpha<\alpha_{\max }$. A schematic presentation for three crystal 


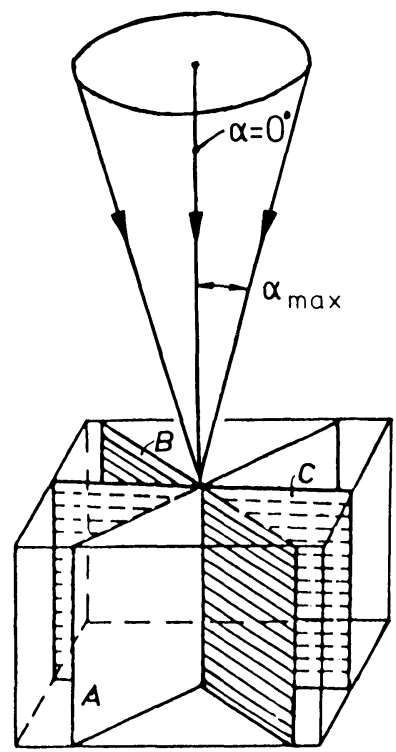

a)

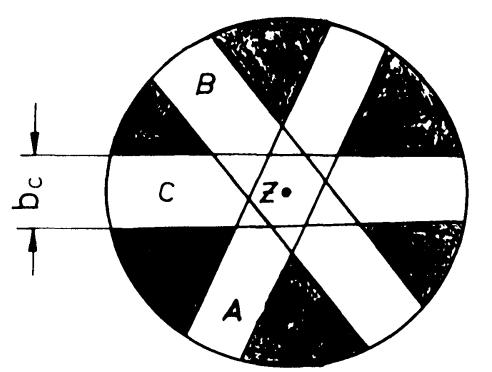

b)

Figure 1 a) Three lattice planes $A, B$ and $C$ of a crystal and incident electron beam with angle $\alpha=0$ and $\alpha_{\max } b_{c}$ : band width; $Z$ : central point, b) SAECP, if only the three lattice planes of Figure 1a fulfil the Bragg condition for incident beam angles between $\alpha=0$ and $\alpha_{\max } . b_{c}$ : width of band $C$. $Z$ : central point.

lattice planes each with different Bragg angle $\theta$, is given in Figure 1a. It is assumed that the angle $\alpha$ can be varied in such a way that the Bragg condition $\alpha=\theta$ can be fulfilled for the lattice planes in this example. In this case, the selected area electron channelling pattern, schematically represented, looks like Figure $1 \mathrm{~b} . Z$, the central point, is the position for $\alpha=0$. There are three bands 
corresponding to the three lattice planes. The width $b$ of the bands is given by

$$
b=c_{1} \cdot \frac{\lambda}{a} \sqrt{h^{2}+k^{2}+l^{2}}
$$

where $\lambda$ is the wave length of the electron beam, $a$ is the lattice parameter of the material and $h, k, l$ are the indices of the lattice plane for which the Bragg condition is fulfilled. The constant $c_{1}$ incorporates the instrument adjustments such as magnification and distance between specimen and detector. $c_{1}$ must be determined experimentally using a crystal with known orientation. In practical applications the angle $\alpha$ is limited to $7^{\circ}$, therefore the diameter of a SAECP is restricted to roughly $14^{\circ}$. An example is given in Figure 2.

\section{DEFINITION OF ORIENTATION}

For texture investigations of deep drawing steels the orientation of a crystal is given in relation to the specimen coordinate system defined by the rolling direction, normal direction and transverse direction, Figure 3 . The orientation of a crystal is then defined by the indices $(h k l)$ of the lattice parallel to the sheet surface, and the direction $[u v w]$ parallel to the rolling direction (Hansen et al., 1978). This description is easily visualized but is mathematically overspecified. Three angles are sufficient for the description of the orientation and the three Euler-angles are normally used (Bunge, 1982, Hansen et al., 1978). Both descriptions are used in this work.

\section{DETERMINATION OF ORIENTATION}

In the following it is assumed, that the surface of the specimen is parallel to the surface of the sheet and perpendicular to the incident electron beam for $\alpha=0$. In Figure 4 some bands and indexed poles between the poles (111), (011) and (001) are given for a bcc crystal. All possible orientations can be represented by two such stereographic triangles which are symmetrical to each other. By tilting an $\mathrm{Fe}-3 \% \mathrm{Si}$ single crystal in the microscope the orientation maps 


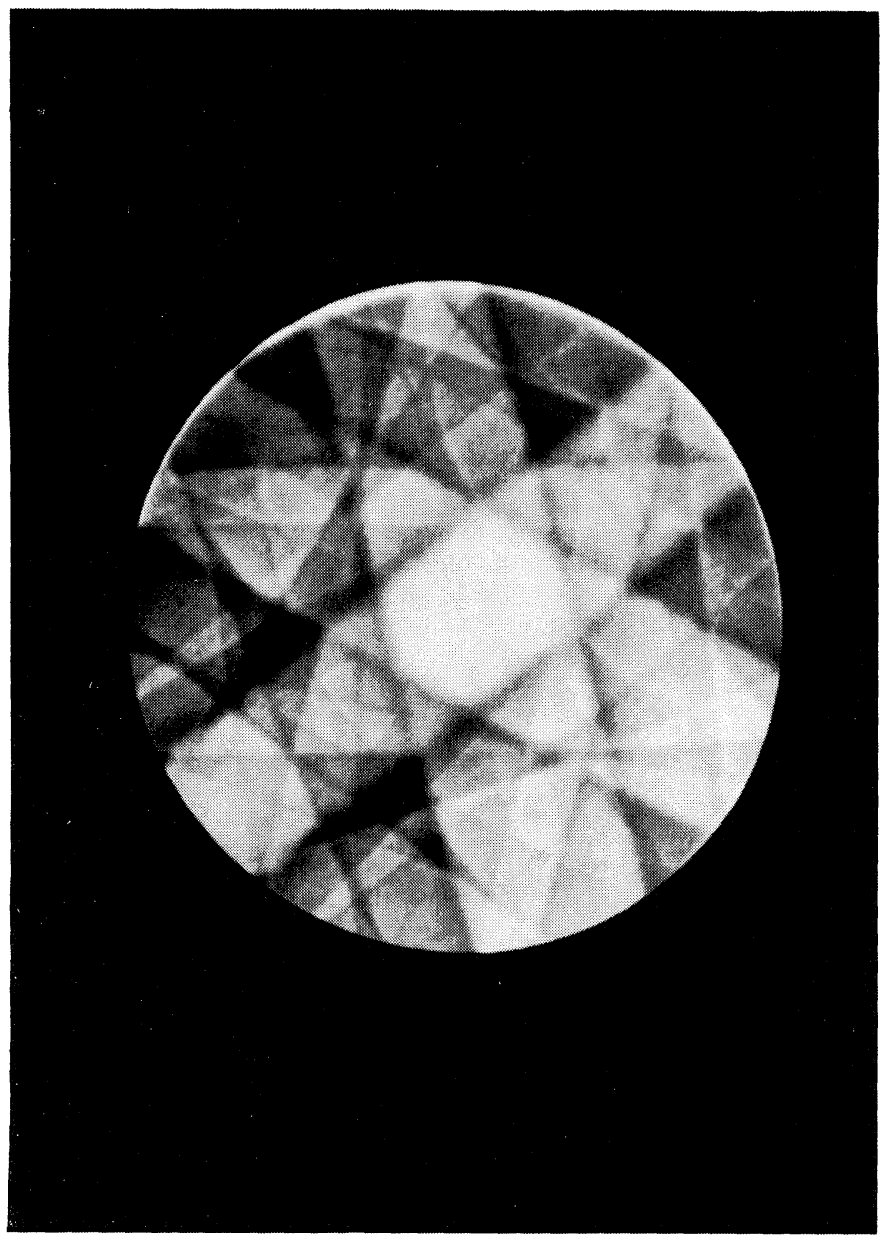

Figure 2 SAECP for a single crystal of $\mathrm{Fe}-3 \% \mathrm{Si} . \alpha$ was varied between $0^{\circ}$ and $8^{\circ}$.

presented in Figure 5 were generated. When comparing SAECP's (Figure 2) with a map (Figure 5), the point on the map that coincides with the central point $Z$ of the pattern (see Figure 1b) corresponds to the orientation (i.e. $h k l$ value) of a plane perpendicular to the incident electron beam when $\alpha=0^{\circ}$. The use of both the symmetric maps is necessary, if the difference between the orientations of two grains will be determined. 


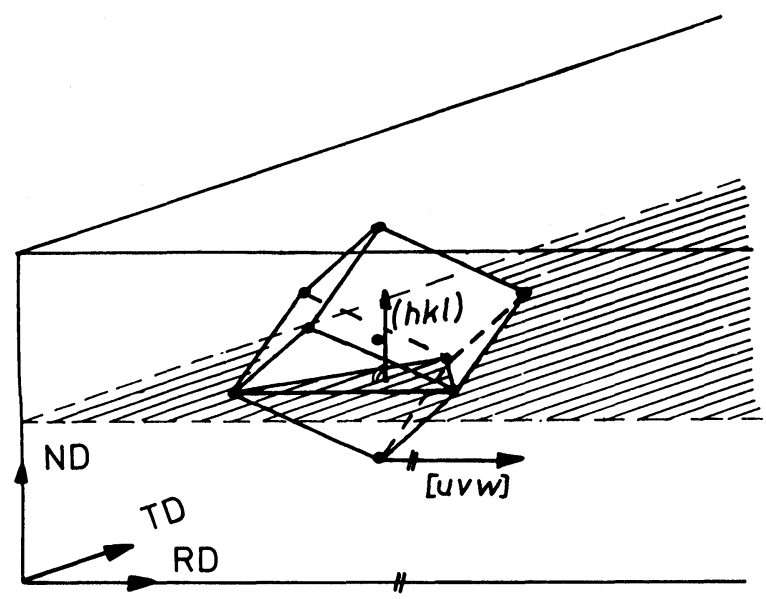

Figure 3 The definition of orientation in sheets of deep drawing steel. ND: normal direction; TD: transverse direction; RD: rolling direction.

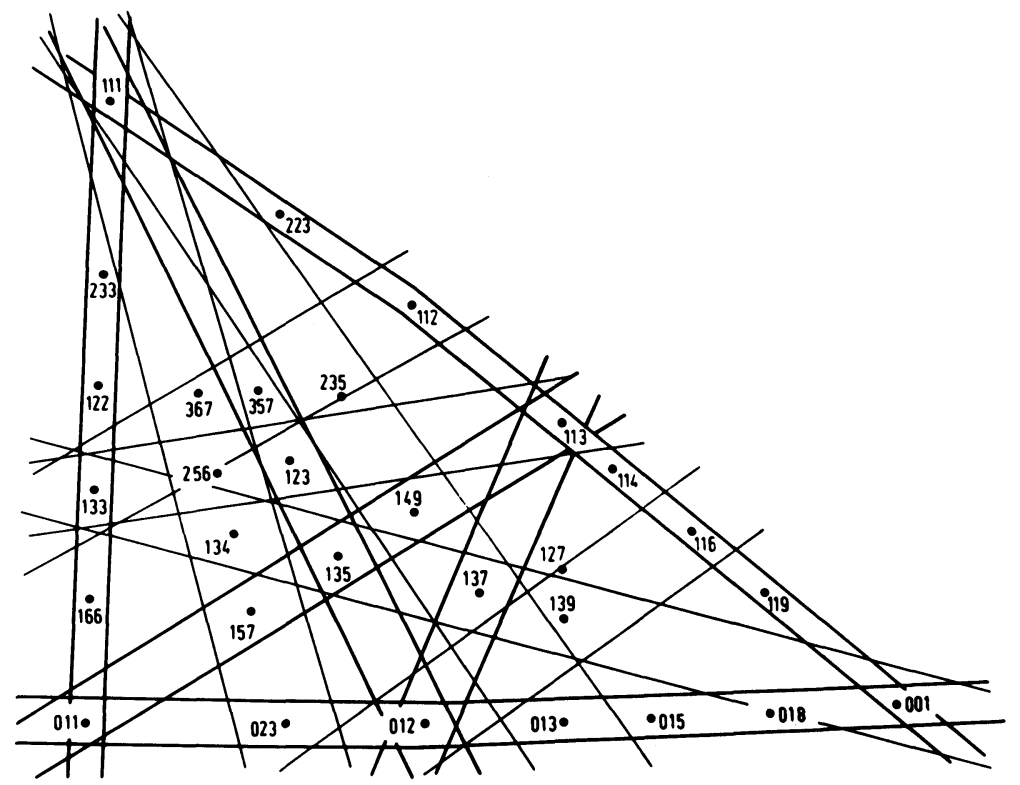

Figure 4 Schematic orientation map of the (111), (011) and (001) stereographic triangle with some bands and indexed poles. 


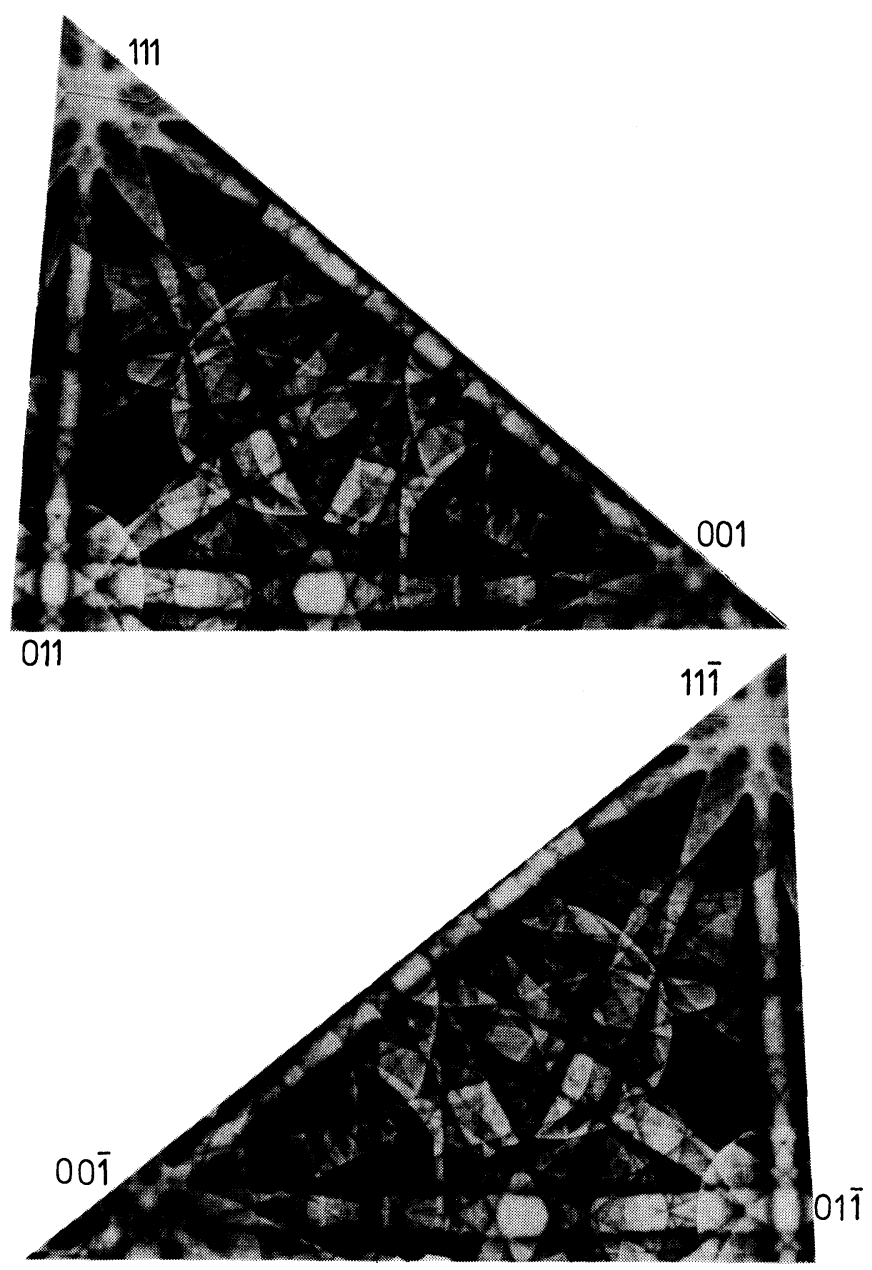

Figure 5 Channelling map for bcc crystals measured with a Fe-3\% Si single crystal: the two symmetric unit triangles.

\subsection{Mapping method}

For a rough determination of the $(h k l)$-orientation the measured pattern, such as Figure 2, is matched with a corresponding part of the maps, Figure 5. If a transparent overlay, on which the main $(h k l)$ orientations (i.e. the main poles) are marked as in Figure 4, is 
used, the $(h \mathrm{kl})$ orientation of the crystal can be obtained readily. The orientation is given by the index of the pole next to the position of the central point $Z$ of the picture (Klaffke, 1978). With this technique the error will be in the range of $5^{\circ}$. To obtain the [uvw] orientation of the crystal it is necessary to tilt the specimen in the microscope by an angle $\beta$ and to determine the new orientation as $\left(h^{\prime} k^{\prime} l^{\prime}\right)$. From the $(h k l)$ and $\left(h^{\prime} k^{\prime} l^{\prime}\right)$ values the $[u v w]$ values can be calculated with Eq. (3). The error in the values of [uvw] calculated this way can be estimated as $\frac{90}{\beta} \cdot 5$ degrees. Another method for the determination of $[u v w]$ is described below.

\subsection{Fixed pole method}

It is much more precise, when the position of the pattern on the map is determined by quantitative measurement of the distance of its central point $Z$ from three reference poles. The principle is described in literature for any combination of reference poles (Klaffke, 1978). Tests have shown that the measurement is much faster if the fixed poles (111), (011), (001) and (111) , (01) $),(00 \overline{1})$ (see Figure 5) are used as reference poles. In this case the position of the measured pattern on the map is determined by measuring the distances $d_{1}, d_{2}$ and $d_{3}$ from the central point $Z$ to the three poles by rotatable rulers mounted on these three poles. For calculation purposes, the indices $h_{n}, k_{n}$, and $l_{n}$ are introduced, which are normalized to the unit vector length. These indices $\left(h_{n} k_{n} l_{n}\right)$ of the plane parallel to the sheet surface are given by:

$$
\begin{aligned}
l_{n} & =\cos \left(c_{2} \cdot d_{3}\right) \\
k_{n} & =\sqrt{2} \cdot \cos \left(c_{2} \cdot d_{2}\right)-l_{n} \\
h_{n} & \left.=\sqrt{3} \cdot \cos \left(c_{2} \cdot d_{1}\right)-l_{n}-k_{n}\right)
\end{aligned}
$$

where $c_{2}$ is a constant incorporating $c_{1}$, see Eq. (1), and other constants such as the magnification of the map. For the determination of $[u v w]$ the direction of the line through $Z$ representing the rolling direction in the pattern must be known, Figure 6 . On this line any point $R$ can be taken to calculate the orientation $\left(h_{n}^{\prime} k_{n}^{\prime} l_{n}^{\prime}\right)$ according to the equations $(2 \mathrm{a}-\mathrm{c})$. The direction $[u v w]$ is then given 


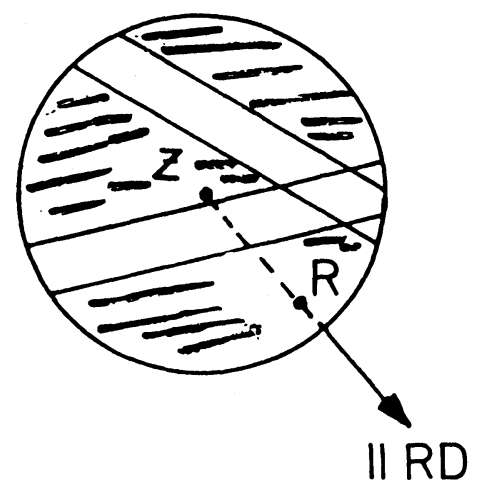

Figure 6 The determination of the direction [uvw] RD: rolling direction; $Z$ : central point.

by:

$$
\left(\begin{array}{c}
u \\
v \\
w
\end{array}\right)=\left(\begin{array}{l}
h_{n} \\
k_{n} \\
l_{n}
\end{array}\right) \times\left(\begin{array}{c}
h_{n}^{\prime} \\
k_{n}^{\prime} \\
l_{n}^{\prime}
\end{array}\right) \times\left(\begin{array}{l}
h_{n} \\
k_{n} \\
l_{n}
\end{array}\right)
$$

With this method the complete orientation can be obtained rapidly.

Depending on the instrument used, there are two ways to establishing the direction of the line representing the rolling direction. In the first, when there is no rotation of the picture between the image mode and the SAEC mode, tests have shown that the best is to adjust the specimen in the image mode, by rotation around its normal direction, in such a way that the rolling direction is horizontal on the monitor. In this case, in the SAEC mode, the line representing the rolling direction is also horizontal. That means that any position on a horizontal line through the point $Z$ can be used to define a point $R$ and to obtain the values $\left(h_{n}^{\prime} k_{n}^{\prime} l_{n}^{\prime}\right)$ for the calculation of [uvw] according to Eq. (3).

In the second, when there is a rotation of the picture between the image mode and the SAEC mode, the direction of the movement of the central point $Z$ must be measured by a rotation of the specimen around the transverse direction.

\subsection{Band method}

If the pattern cannot be matched with the map, the orientation can be calculated by a method represented in Figure 7. In principle, the 


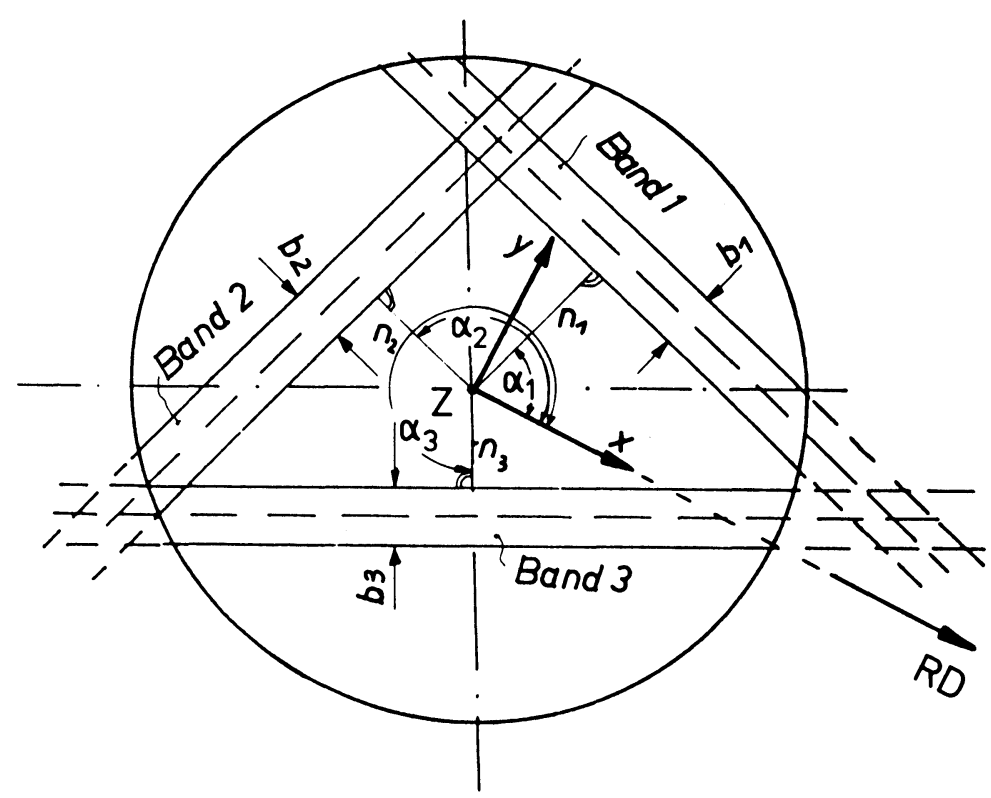

Figure 7 The determination of the orientation by the measurement of three bands. The $x$-axis is parallel to the rolling direction (RD). The origin of the coordinate system is the central point $Z$.

$(h \mathrm{kl})$ values are calculated from the position of three bands (Klaffke, 1978). For the calculation of the band-indices, the distances $n_{i}$, the angles $\alpha_{i}$ and the band widths $b_{i}$ must be determined. The angles $\alpha_{i}$ are defined to a $x-y$-coordinate system with $x$ parallel to the rolling direction. The easiest way for the calculation is to determine the equations for the lines, forming the boarders of the bands. From these equations the angles between the bands and the band indices can be calculated. From the band indices the pole indices are determined and then the value $(h k l)$ (Klaffke, 1978, Lorenz, in preparation). To get [uvw], on the $x$-axis any point can be taken for the calculation according to Eq. 3 .

The advantage of this method compared with that described in literature (Klaffke, 1978) is that it is not necessary to have three poles in the measured pattern and no additional input is required for the determination of $[u v w]$ (Lorenz, in preparation). 


\section{ERROR ESTIMATION}

The total error for the orientation determination is a sum consisting of the error made in specimen preparation $\left(\sim 0.5^{\circ}\right)$, the angular deviation when mounting the specimen on the stage $\left(\sim 0.5^{\circ}\right)$, the error in the imaging by the instrument $\left(\sim 0.2^{\circ}\right)$ and the error in the data evaluation $\left(0.5^{\circ}\right.$ for $(h k l)$ and $2-3^{\circ}$ for $[u v w]$ for the methods described in Chapters 4.2 and 4.3). The total absolute error then varies from $1.5^{\circ}$ to $2^{\circ}$ for $(h k l)$ and $3^{\circ}$ to $4^{\circ}$ for [uvw]. Of course the uncertainty for the difference in the orientation between two crystals is much less and may be in the range of $0.5^{\circ}$ for $(h k l)$ and $2.5^{\circ}$ for $[u v w]$. The error of $[u v w]$ is greater than that of $(h k l)$ because, according to Eq. 3, small variations in the determined values for $(h k l)$ or $\left(h^{\prime} k^{\prime} l^{\prime}\right)$ give rise to great errors in [uvw]. Repeated measurements of the same crystal in a specimen after removal from the stage of the microscope and readjustment confirmed these error estimations. However, to maintain such a small error margin it is necessary to keep a standard specimen on the stage, never removed, to eliminate additional deviations, e.g. from instrumental adjustments.

\section{TIME}

Figure 8 shows an example of a measurement. From the micrograph Figure $8 \mathrm{~b}$ the outlines of the grains are derived by image analysis (see section 7). Each grain is numbered and thus identified. Grains without number are too small to produce a pattern by SAEC. Several minutes are required to determine the orientation of a grain and approximately 60 hours are needed for 400 grains. In some cases, this number of grains is already representative for a specimen as will be indicated below.

\section{IMAGE ANALYSIS}

For the calculation of an ODF the orientations of the crystals and their individual volume fraction must be known. It can be derived from stereological principles, that the volume fraction equals the 

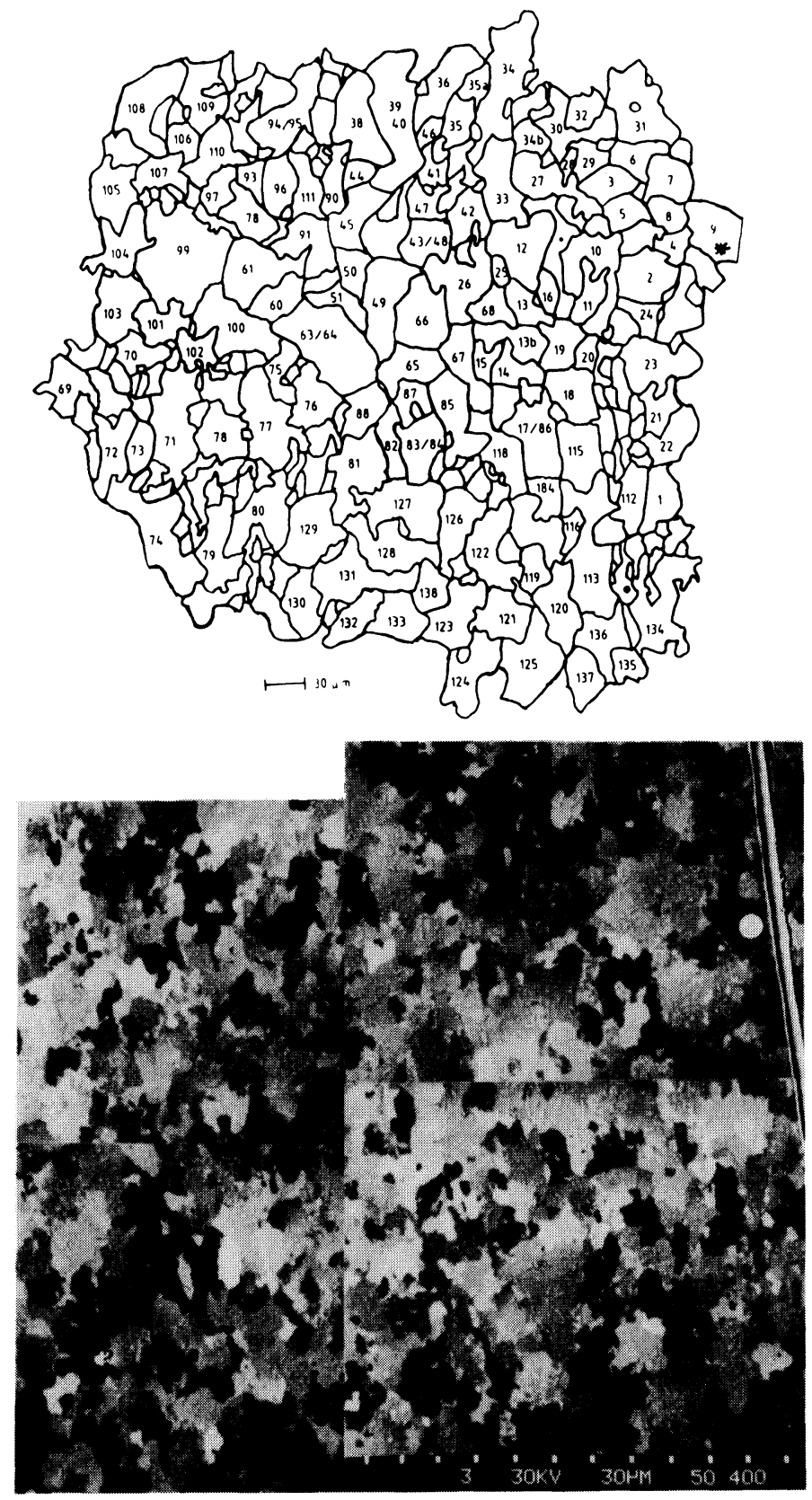
area fraction (Underwood 1970) if the phases under consideration are random distributed. To get the volume fraction, the area of each grain was measured by an image analyser. This has the advantage, that besides the area for each grain its shape and position relative to other grains can be measured at the same time. In Figure $8 \mathrm{~b}$ not all areas, which have one grey level represent an individual grain. However, by changing the $x-y$-position of the specimen and observing the change of the picture in the image mode, most of the grain boundaries can be defined, but a final decision on the dimension of one grain can only be made with the SAEC mode. This measurement has e.g. shown, that the "two" grains 63 and 64, defined in the image mode, have the same orientation. Evaluation of data has shown, that for the material investigated there is no correlation between the area of the grains measured in the section and its orientation. Therefore the distribution can be assumed to be random and the area fraction equals the volume fraction. By additional storage of the measured orientation all data is available to calculate the output data. Figure 9 gives a schematic illustration of data processing routes.

\section{PRESENTATION OF RESULTS}

To plot the $(h k l)$ or $[u v w]$ values in one of the two stereographic triangles is a visual representation of the measured orientations of individual grains. Figure 10 shows a plot of $(h k l)$ values in which three ranges of $[u v w]$ are marked by different symbols to get a rough estimation of the three-dimensional distribution. For a presentation in the Euler space, in principle, it is only necessary to plot each measured orientation lying in the usual sections through the Euler space which have an interval of $5^{\circ}$. But from 400 measured grains only some will be present in the 19 sections. To get more values plotted in one section, all orientations within $\pm 2.5^{\circ}$ distance from each section are plotted in the section, Figure 11. In

Figure 8 a) Grain boundaries derived from Figure $8 b$. The orientation of each numbered grain is measured, b) SEM micrograph taken in backscattering mode. Deep drawing steel with $0.04 \% \mathrm{C}$ and $0.2 \% \mathrm{Mn}$. Completely recrystallized at $550^{\circ} \mathrm{C}$. Grain number 9 at the right side is marked in both figures by "*". 


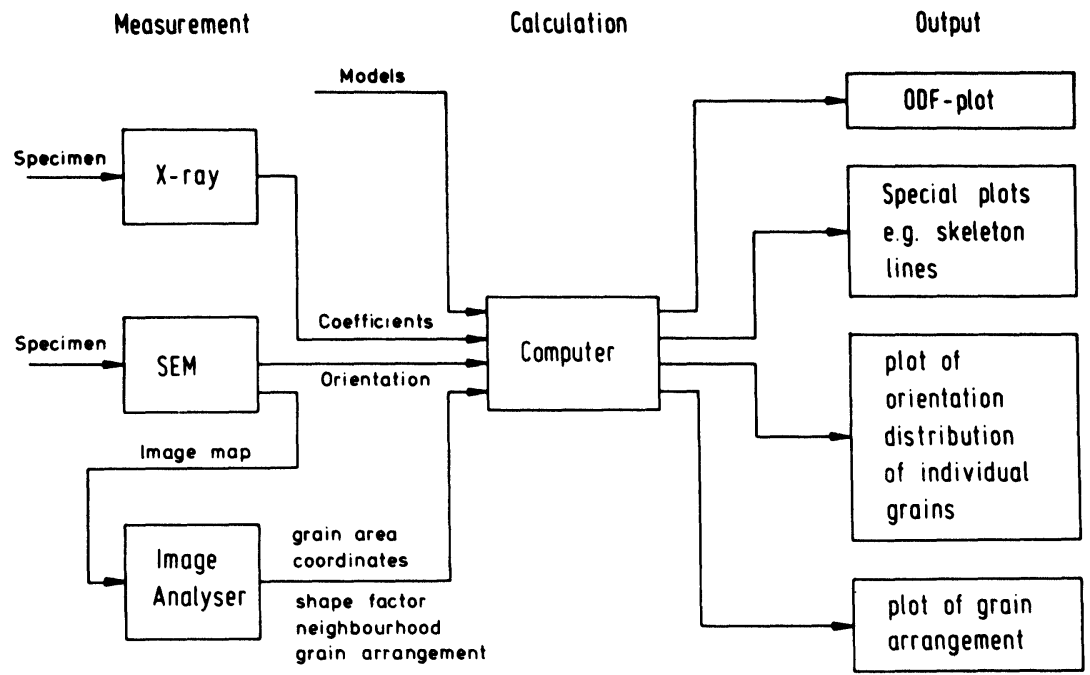

Figure 9 Data connection between the results from x-ray measurement, the SEM and the image analyser.

this plot the volume fraction of each grain is not considered. But 270 or 400 values are too small a number for a comparison with an ODF determined by $\mathrm{x}$-rays. It was necessary to assume a Gauss distribution around each measured orientation. With these assumptions an ODF can be calculated, if a standard deviation $\sigma$ is defined for the single orientations. This is done in such a way that the intensity of the ODF calculated from single orientation measurements is in the same range as that of the ODF obtained by $x$-rays. Additionally, the volume fraction of each measured crystal is considered. The result is presented in Figure 11 by solid lines. The comparison with the points representing the measured orientations of the individual crystals shows that the point density is highest near the highest intensity of the ODF. In Figure 12 the ODF determined with $\mathrm{x}$-rays is presented. The comparison with Figure 11 shows, that there is a good agreement between the ODF of a large number of grains as determined by $x$-rays (Figure 12) and the orientations of 270 individual grains (Figure 11). Both ODF's have a strong (111)-fibre. There is only a shift from the (111) [110] peak in the 


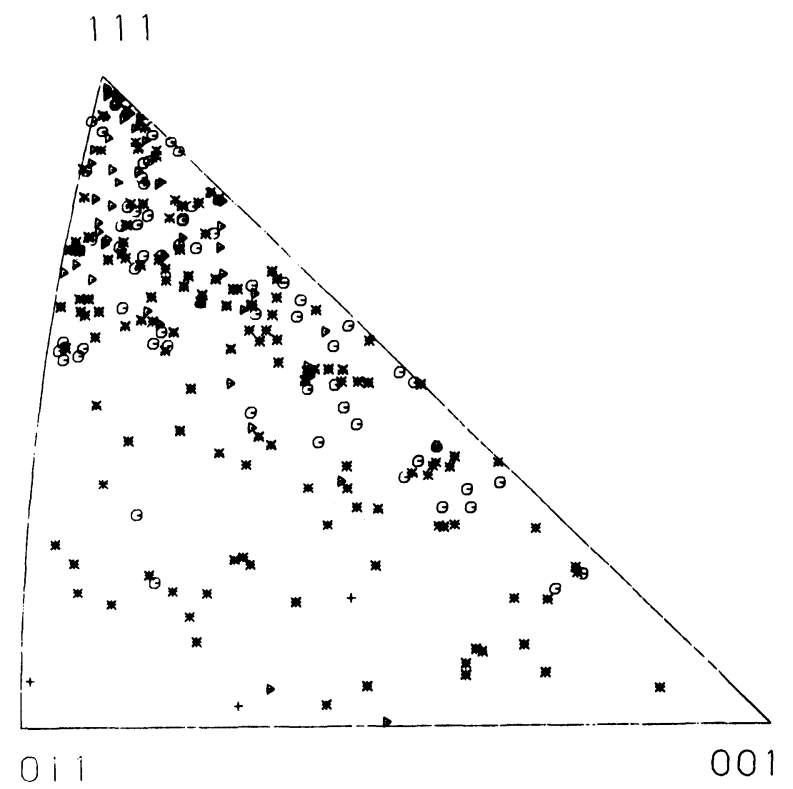

Figure 10 One unit triangle with the $(h k l)$ orientation of individual grains. The $[u v w]$ directions are summarized by three symbols:

$\mathrm{O}:[011] \pm 10^{\circ}$

$\triangle:[112] \pm 10^{\circ}$

$+:[001] \pm 10^{\circ}$

*: all other orientations

Steel and heat treatment see Figure 8. 270 grains measured.

x-ray measurement to (111) [112] in the measurement of individual grains.

\section{CORRELATION OF ORIENTATIONS}

The shape, position and orientation of each grain is stored in the computer (see Figure 9) and it is therefore possible to plot the angle between two grains on a line connecting the centers of gravity of the grains, Figure 13. The rotation axis is not specified in this plot. It can be seen, that two neighbouring grains often have large angles in 


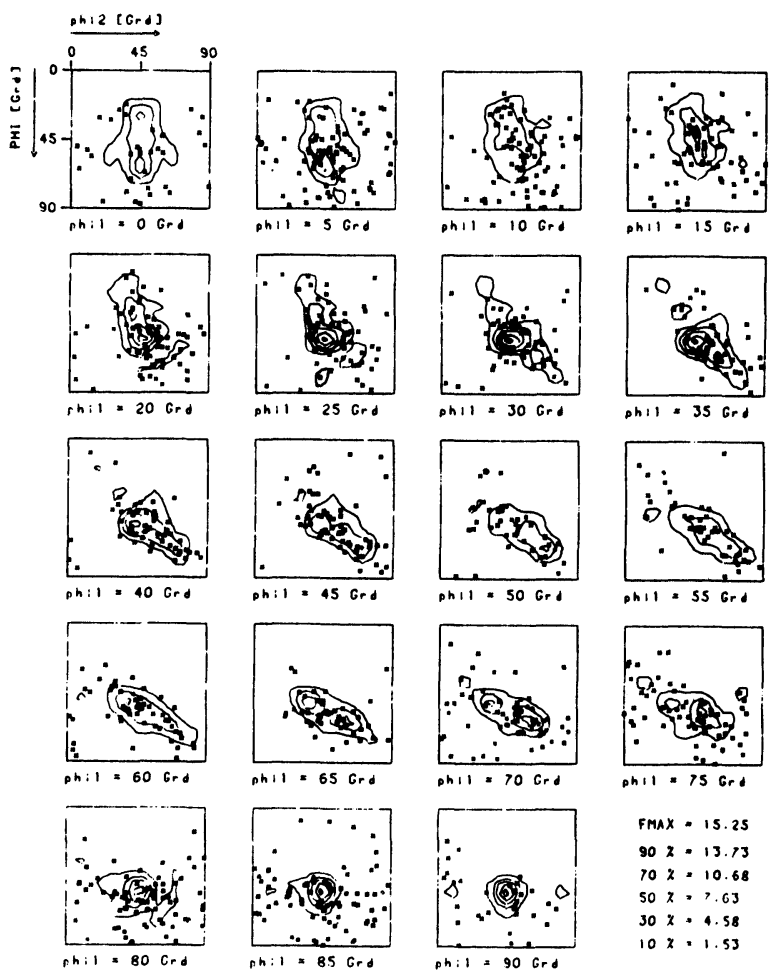

Figure 11 Presentation of the same values as in Figure 10 in the Euler space $\left(^{*}\right)$ and from these points calculated ODF (lines).

the range of $40^{\circ}$ or $50^{\circ}$. This is discussed in details elsewhere (Lorenz, in preparation). Of course there are further ways to present the distribution of angles (Plege, 1986).

\section{STATISTICS}

To get an unbiased result in each field of view all grains that had a sufficient size were measured. In general, several measuring fields were positioned on the specimen field by field to get a total number of about 150 grains. Then the same arrangement was made at another position on the specimen. With the results from different 

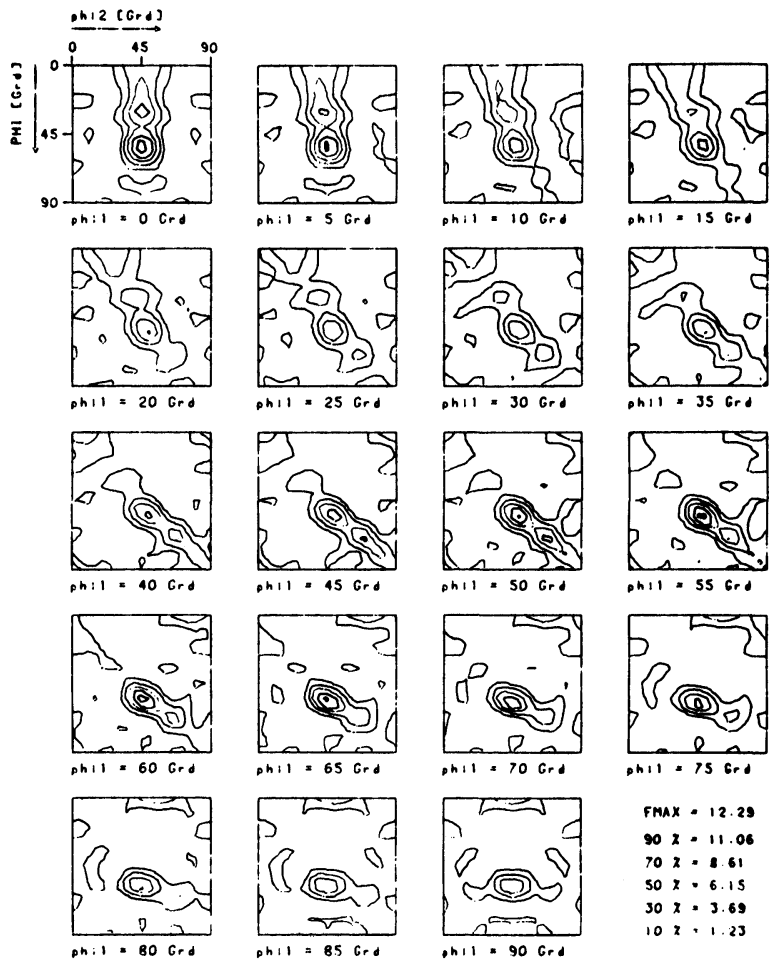

Figure 12 ODF determined by $x$-ray analysis. Conditions see Figure 8.

areas the ODFs were calculated and compared for one specimen. The data presented in Figure 11 are the sum of the measurements of two such areas. Each data set, containing about 130 grains, has a different ODF. On the other hand, the data presented in Figure 14 is also the sum of two sets of about 200 grains each, but the ODF's of these sets are nearly identical. Therefore it must be checked in each case how many measurements are necessary to get a sufficient precision of the mean.

\section{DISCUSSION OF RESULTS}

The examples given above are results of measurements of a deep drawing steel with $0.04 \% \mathrm{C}$ and $0.2 \% \mathrm{Mn}$. After hot rolling the 


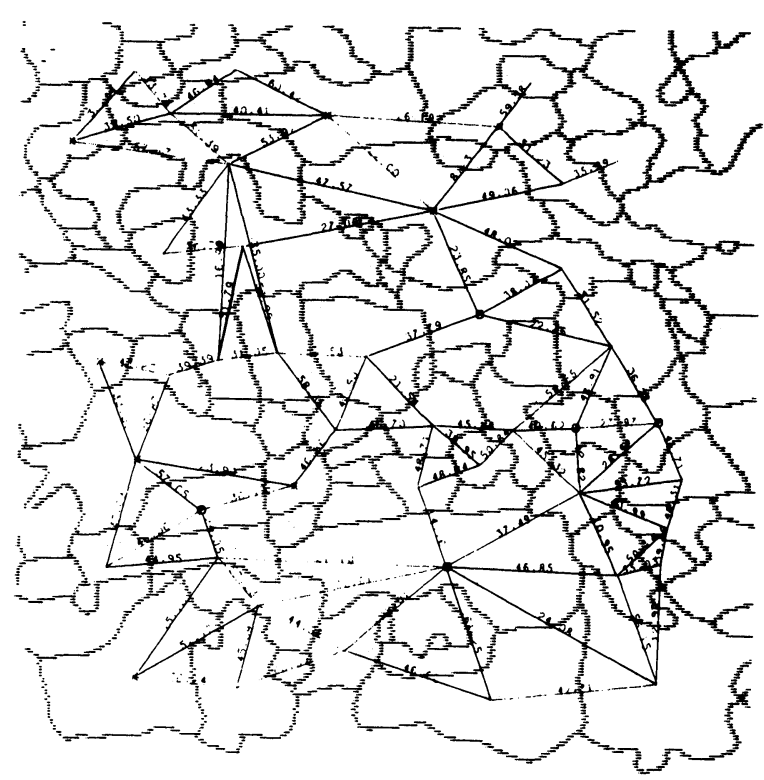

Figure 13 Angle between neighbouring grains. Steel and heat treatment see Figure 8.

material was coiled at $550^{\circ} \mathrm{C}$. The deformation during cold rolling was $70 \%$. After annealing at $550^{\circ} \mathrm{C}$ for 30000 seconds the material was completely recrystallized. In this condition it has a pronounced (111) texture, Figure 11 and Figure 12 (Lorenz, in preparation). After annealing at $550^{\circ} \mathrm{C}$ for 1000 seconds the ODF measured by $\mathrm{x}$-rays shows no change when compared with the ODF of the cold rolled material. But the measurement of the recrystallized grains, with a diameter greater than $7 \mu \mathrm{m}$, Figure 14 , shows clearly that there is already a texture similar to that after complete recrystallization.

In this case, the start of the recrystallization is decisive for the development of the final texture. Details of the measurements are discussed elsewhere (Lorenz, in preparation). This result could only be obtained by the measurement of individual grain orientations. Only by the combination of different data as illustrated in Figure 9, and appropriate programs was it possible to measure the orientation of so many individual grains, as done in this work (Lorenz, in preparation), and to evaluate all the data in reasonable time. 


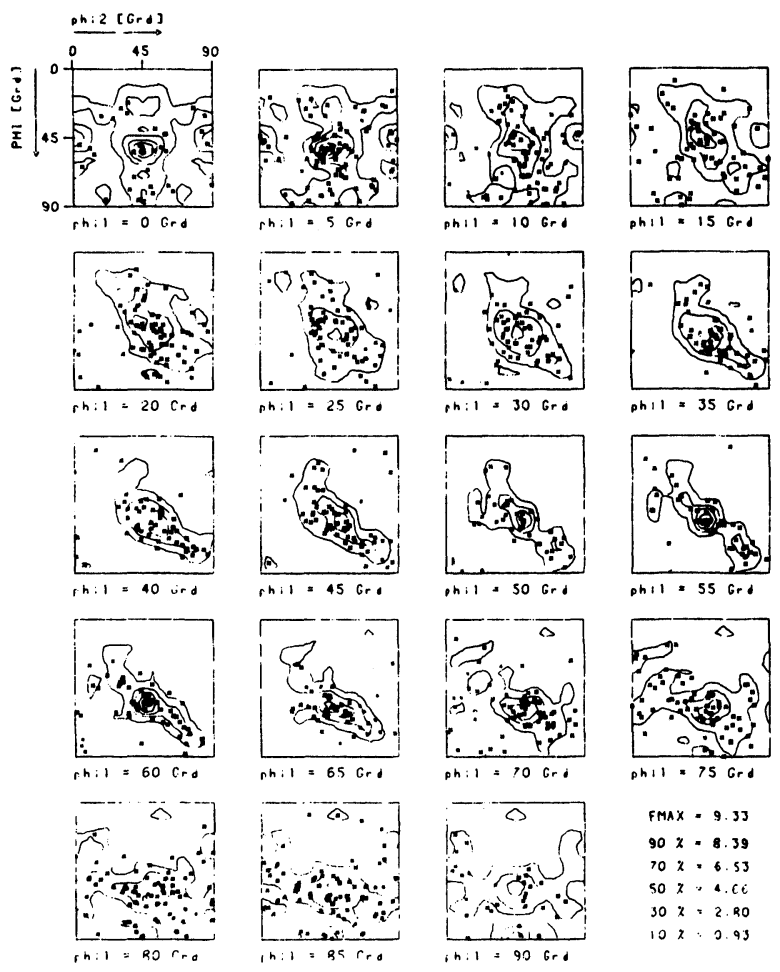

Figure 14 Position of the orientation of individual grains in the Euler space $(x)$ and from these points calculated ODF (lines). Steel as in Figure 8, recrystallization $1000 \mathrm{~s}$ at $550^{\circ} \mathrm{C}$, about $10 \%$ of volume recrystallized. Results of 415 grains.

\section{Acknowledgement}

The authors wish to thank Mr. Matthews for his assistance in translation and the BMFT for financial support.

\section{References}

Bunge, H. J. and Esling, C. (1982). Quantitative Texture Analysis, DGM Informationsgesellschaft, Oberursel.

Bunge, H. J. (1982). Texture Analysis in Materials Science, Butterworths.

Bunge, H. J. (1986). Experimental Techniques of Texture Analysis, In: 
Experimental Techniques of Texture Analysis, p. 1-28, DGM Informationsgesellschaft Oberursel.

Essen van, C., Schulson, E. M. and Donaghay, R. H. (1971). The Generation and Identification of SEM Channelling Patterns from $10 \mu \mathrm{m}$ Selected Areas, J. of Mat. Sci. 6, 213-217.

Hansen, J., Pospiech, J. and Lücke, K. (1978). Tables for Texture Analysis of Cubic Crystals. Springer-Verlag, Berlin-Heidelberg.

Heimendahl, M. von (1970). Einfuhrung in die Elektronenmikroskopie, Vieweg Verlag Braunschweig.

Hirsch, J., Burmester, G., Hoenen, L. and Lücke, K. (1986). Autex III-A High Speed Texture Goniometer and Data Processing System, In: Experimental Techniques of Texture Analysis, p. 63-77, DGM Informationsgesellschaft, Oberursel.

Klaffke, D. (1978). Beobachtung und Orientierungsbestimmung der Oberflächenkristallite polykristalliner $99.999 \%$-Al-Proben bei Biegewechselbeanspruchung, Bundesanstalt für Materialprüfung Forschungsbericht 55, Berlin.

Klein, H. and Bunge, H. J. (1986). The Texture Goniometer ATEMA-C, In: Experimental Techniques of Texture Analysis, DGM Informationsgesellschaft, Oberursel p. 51-62.

Kubalek, E. (1973). Electron Channelling Patterns im Rasterelektronenmikroskop-Entstehung, Deutung und Anwendung, Härterei Technische Mitteilungen 28, 300-306.

Lane, L., Pease, E. and Nelson, C., Erzeugung von Channelling Diagrammen mit dem Rasterelektronenmikroskop, Siemens Analysetechnische Mitteilungen Nr. 109.

Lorenz, W., Ph. D. Thesis in Preparation.

Plege, B., (1986). The Determination of Orientation Correlation Functions in Two Phase Fibre Composites, In: Experimental Techniques of Texture Analysis, p. 315-328, DGM Informationsgesellschaft, Oberursel.

Reimer, L. and Pfefferkorn, R. (1977). Rasterlektronenmikroskopie, Springer Verlag Berlin.

Thönnessen, A. (1987). Ermüdungsrißbildung an Cu-polykristallen, Dissertation RWTH Aachen.

Underwood, E. (1970). Quantitative Stereology, Addison-Wesley Publ. Company, London.

Watanabe, T. (1984). The Anisotropy of Grain Growth due to the Migration of Plane-Matching Grain Boundary in Fe-3\%-Si, 7th International Conference on Textures of Materials. Noordwijkerhout (NL), p. 307-312.

Weiland, H. and Schwarzer, R. (1986). On Line Texture Determination by Kikuchi or Channelling Patterns. In: Experimental Techniques of Texture Analysis, p. 301-314, DGM Informationsgesellschaft, Oberursel.

Weiss, B., Hughes, C. W. and Stickler, R. (1971). SEM-Techniques for the Microcharacterization of Metals and Alloys. Praktische Metallographie Nr. 8, $477-491$.

Welch, P. I. (1986). Neutron Diffraction Texture Analysis, In: Experimental Techniques of Texture Analysis, p. 183-208, DGM Informationsgesellschaft, Oberursel. 